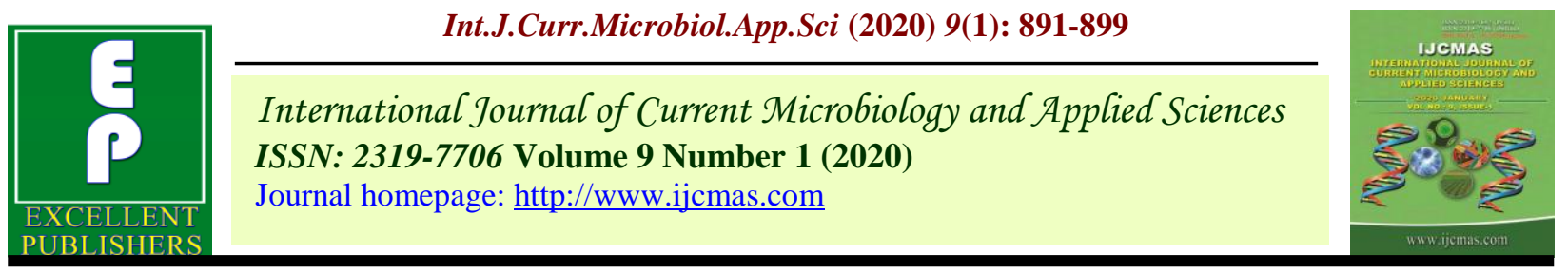

Original Research Article

https://doi.org/10.20546/ijcmas.2020.901.099

\title{
Menstrual Hygiene Management among Rural Adolescent Girls of Agrarian Families
}

\author{
V. Kavitha Kiran and K. Yashoda* \\ All India Coordinated Research Project on Home Science, Human Development Component, \\ PGRC, PJTSAU, Rajendranagar, Hyderabad-30, India \\ *Corresponding author
}

\begin{tabular}{|l|}
\hline Ke y w o r d s \\
Hygienic practices, \\
Menarche, \\
$\begin{array}{l}\text { Reproductive tract } \\
\text { infections, Sanitary }\end{array}$ \\
\hline Article Info \\
\hline $\begin{array}{l}\text { Accepted: } \\
15 \text { December } 2019 \\
\text { Available Online: } \\
\text { 20January } 2020\end{array}$ \\
\hline \hline
\end{tabular}

The study was planned to assess the Menstrual Hygiene Management of Rural adolescent girl's. The source of information regarding menstruation, and also to assess hygiene practices among them. Exploratory study was conducted with focused group discussions and self reported questionnaire. The study was carried out in Rural Telangana area. Major findings of the study were, that among the 120 adolescent girls, $68 \%$ were between 13 and 16 years. A maximum of $37 \%$ were having first menarche at the age of 12 13yrs. $76 \%$ had regular cycles. Maximum 56\% had Medium Menstrual flow usually. About $86 \%$ girls used sanitary pad and the rest used cloth pieces. About $39 \%$ used water and no soap for hand washing. Multiple restrictions were practiced. Conclusion: This study reported that menstrual hygiene was unsatisfactory among adolescent girls. Therefore, girls should be educated about the facts of menstruation and proper hygienic practices.

\section{Introduction}

Menstrual Hygiene Management is defined as 'Women and adolescent girls using a clean menstrual management material to absorb or collect blood that can be changed in privacy as often as necessary for the duration of the menstruation period, using soap and water for washing the body as required, and having access to safe disposal. The goal of menstrual hygiene management is to ensure that women and girls can manage their periods in a way that is not only healthy, but that enables their full participation in school, work, and other activities.

Menstruation is a natural process but it is still a taboo in Indian society as it is considered unclean and dirty Unfortunately, due to lack of knowledge on menstruation preparedness and management or due to shyness and embarrassment the situation becomes worse 
for girls Menstruation wastes are the wastes that are generated by a female in her reproductive years. These wastes are produced during menstruation commonly known as menses, periods, or monthly bleeding cycle.

The menstrual cycle has three phases, that is, follicular phase (proliferative), ovulation phase, and luteal phase (secretory). Menstruation is regulated by hormones; in this process, endometrium, lining of uterus, gradually thickens and sheds off and causes bleeding that normally last for 3-5 days and occasionally up to 7 days. Menstruation sheds two-thirds of the endometrial lining. In addition to blood, menstrual fluid contains mucus and vaginal secretions.

The color of the menstrual fluid varies between red, bright red, and dark brown to black. Menstrual fluid may or may not have unpleasant odor especially when it comes in contact with air. Menstrual flow or duration also changes before menopause or during gynecological cancers.

Under conditions of hormonal imbalance, fibroids, polyps, and endometriosis menstrual flow increase and excessive loss of blood through menstruation can lead to anemia Menstrual flow was seen as dirty, polluting, and shameful, so women hide menstrual cloths for fear of being cursed.

In similar findings, it was believed that menstrual waste was linked to witchcraft and danger, so it must be buried unless witches go after human blood and find the menstrual wrapper/cloth and destroy the women by causing infertility.

Education plays a key role in menstruation hygiene management. By educating both men and women regarding menstruation, we can overcome these false beliefs and taboos.

\section{Objective}

- Menstrual Hygiene Management among Rural Adolescent Girls for Personal and Environmental Hygiene.

- To find out the prevailing practices for menstrual hygiene among adolescent girls.

- To assess the awareness about menarche and their sources of information before its onset.

\section{Rationale}

Menstrual hygiene management (MHM) is an essential aspect of hygiene for women and adolescent girls between menarche and menopause. Despite being an important issue concerning women and girls in the menstruating age group MHM is often overlooked in post-disaster responses. Menstruation and menstrual practices still face many social, cultural, and religious restrictions which are a big barrier in the path of menstrual hygiene management. In many parts of the country especially in rural areas girls are not prepared and aware about menstruation so they face many difficulties and challenges at home, schools, and work places. While reviewing literature, we found that little, inaccurate, or incomplete knowledge about menstruation is a great hindrance in the path of personal and menstrual hygiene management. Girls and women have very less or no knowledge about reproductive tract infections caused due to ignorance of personal hygiene during menstruation time. As a result, they feel subnormal, diseased, or traumatized Unprepared girls were frightened, confused, and feel embarrassed by menarche likely to develop negative attitudes towards menstruation. Poor menstrual hygiene management has been shown to result in a sense of shame, anxiety, and embarrassment 
that contributes to absenteeism and poor performance at school.

The objectives of this study were to determine the percentage of girls absent from school during menstruation, to evaluate the various factors associated with school absenteeism during menstruation, and to assess the practices regarding menstrual hygiene.

Good menstrual hygiene is crucial for both physical and mental health, education, and dignity of adolescent schoolgirls.

\section{Materials and Methods}

Sample was identified from the adopted villages namely Pendyala, Kalvakol, Subhanpura, Kollapadkal and Rama chandraguda (5) of Maheshwarammandal, RR District, Hyderabad.

\section{Research design}

Exploratory study was carried out in field practice area of the Maheswaram Mandal, Ranga Reddy District.

\section{Sample}

The study was undertaken among the 120 adolescent's girls between 11 and 16 years of age in the Agrarian families. This study was carried out in a period of 3 months

\section{Tools}

Menstrual Hygiene Practices checklist was developed by AICRP-CD, Hyderabad Unit (2019) to find out the Knowledge levels of adolescent girls with regard to Menstrual Hygiene. It was pre tested and administrated to the sample. The data collected was coded, analyzed and presented in the following tables.

\section{Results and Discussion}

From table 1 it could be said that $32 \%$ of the sample were in age 11-13yrs and $68 \%$ of them in age group 13-16yrs. The table concludes that majority of the sample in 1316 years age group.

Table 2 provides information about the age menarche of the selected adolescents, $37 \%$ of the selected sample age was 12-13yrs and $30 \%$ were of $11-12 \mathrm{yrs}$ at time of their first cycle. The study further noted that $23 \%$ had their menarche at 13-14yrs of age while menarche age of $3.5 \%$ was 9-10years followed by $6.5 \%$ at $10-11 \mathrm{yrs}$ of age.

With regard to number of days in each cycle majority of the selected sample $(45 \%)$ had 3 5days, $30 \%$ had 2-3days and $24 \%$ had 1 2 days of blood flow in each cycle (Table 3 ).

From table 4 it could be inferred that $72 \%$ of them had regular and $28 \%$ had irregular periods.

With regard to heavy menstrual flow the study concludes that $56 \%$ more than half of the sample had medium blood loss while $40 \%$ experienced low and 4\% heavy menstrual flow (Table 5).

With regard to type of material used, it was fund that $80 \%$ of adolescent girls used sanitary napkins, while $20 \%$ used cloth. In all government high schools sanitary napkins are provided to adolescent girls, so majority of them use sanitary napkins (Table 6).

Table 7 provides information with regard to napkin/material change by adolescent girls and it was found that $67 \%$ of them change after 8-12 hours, which was a very harmful practice. 
With regard to personal hygiene practices followed by the adolescent girls during menstruation, revealed that $69 \%$ of them bath during periods but $31 \%$ don't take bath as it is considered as cultural taboo. The study found that $61 \%$ of the sample don't wash hand after changing while only 39\% wash their hands. Using Dettol or any other antiseptic was found only in $21 \%$ of the sample and $79 \%$ of them don't use any kind of disinfectant (Table 8).

With regard to discomforts, the study concluded that $53 \%$ had itching, $26 \%$ headaches during the menstruation, $22 \%$ had nausea. Majority of them had stomach pain (82\%), muscle cramps $(71 \%)$, skin rashes $(53 \%)$, body pains $(43 \%)$ and tiredness $(45 \%)$ (Table 9).

From table 10 it could be inferred that $56 \%$ of the sample throw the used material in dustbin, $7 \%$ wash and reuse them, $21 \%$ burn, $16 \%$ bury them and $3 \%$ flush them into toilets

It was interesting to note from the study that $48 \%$ of the girls miss school for 1-2 days during their menstruation every month while $52 \%$ were absent for 3-5days from school because of the menstrual period (Table 11).

With regard to absenteeism, it was found no facilities for changing and safe disposal were top reasons for school absenteeism during menstruation. Pain (82\%), fear of staining ( $80 \%$ ) found to be next important reason for school absenteeism. Tiredness/Un comfort, no availability of pads was found to be some of the reasons for school absenteeism during menstruation (Table 12).

With regard to menstrual awareness $82 \%$ of the girls know that it is a physiological condition but $56 \%$ feel that it is disease condition. The study found that $48 \%$ of the girls not aware that it is important for child bearing and pregnant women don't menstruate. Majority of the sample aware that menstrual blood as impure and contains harmful substances and physical activities during menstruation as harmful (Table 13).

With regard to activities missed during menstruation, the study concludes that household activities like cooking, cleaning were missed as it is considered taboo. In addition being physically active like playing games. The study also found that they were not allowed to participate in spiritual activities (Table 14).

Menstrual esteem means feeling about oneself or self-confidence during menstrual period. With regard to the Self Esteem $22 \%$ of the sample were Happy with self; $72 \%$ of the sample reported that they are not good; $34 \%$ of the sample felt they are as good as others; $80 \%$ of the sample reported that they Feel like failure; $64 \%$ of the sample were Low confidence levels; $76 \%$ of the sample were Felt like exhausted; Maximum $93 \%$ of the sample were feeling insecured; $77 \%$ of the sample were feeling Shameful and $78 \%$ of the sample were feeling Shyness about menstruation (Table 15).

Table.1 Distribution of sample as per age

\begin{tabular}{|l|l|l|}
\hline $\begin{array}{l}\text { Age of the } \\
\text { Respondent }\end{array}$ & $11-13$ yrs. & $13-16 y r s$ \\
\hline $38(32 \%)$ & $82(68 \%)$ \\
\hline
\end{tabular}


Table.2 Distribution of sample according to age of Menarche

\begin{tabular}{|l|l|l|l|l|l|}
\hline $\begin{array}{l}\text { Age of First } \\
\text { Menstrual }\end{array}$ & 9-10yrs & 10-11yrs & 11-12yrs & 12-13yrs & 13-14yrs \\
\hline & $3(3.5 \%)$ & $8(6.5 \%)$ & $36(30 \%)$ & $45(37 \%)$ & $28(23 \%)$ \\
\hline
\end{tabular}

Table.3 Number of Days of period in each cycle

\begin{tabular}{|l|l|l|l|}
\hline $\begin{array}{l}\text { No.of days of } \\
\text { periods in each cycle }\end{array}$ & $\mathbf{1 - 2}$ days & 2-3Days & 3-5 days \\
\hline $29(24 \%)$ & $37(30 \%)$ & $54(45 \%)$ \\
\hline
\end{tabular}

Table.4 Distribution of sample according to Frequency of cycle

\begin{tabular}{|l|l|c|}
\hline Frequency of Cycle & Regular & Irregular \\
\cline { 2 - 3 } & $86(72 \%)$ & $34(28 \%)$ \\
\hline
\end{tabular}

Table.5 Distribution of sample as per blood loss during the period

\begin{tabular}{|l|l|l|l|}
\hline $\begin{array}{l}\text { How Heavy is the } \\
\text { Menstrual flow } \\
\text { usually }\end{array}$ & low & Medium & High \\
\hline usual $(40 \%)$ & $67(56 \%)$ & $5(4 \%)$ \\
\hline
\end{tabular}

Menstrual Hygiene practices followed by Adolescent Girls

Table.6 Type of material used

\begin{tabular}{|l|l|l|}
\hline Type of Material used & Sanitary Napkin & Cloth \\
\hline & $96(80 \%)$ & $24(20 \%)$ \\
\hline
\end{tabular}

Table.7 Frequency of changing the pads in $24 \mathrm{hrs} /$ one full day

\begin{tabular}{|l|l|l|l|}
\hline $\begin{array}{l}\text { Frequency of } \\
\text { Change }\end{array}$ & $\mathbf{3 - 6 h r s}$ & $\mathbf{6 - 8 h r s}$ & $\mathbf{8 - 1 2 H r s}$ \\
\hline $4(3 \%)$ & $36(30 \%)$ & $80(67 \%)$ \\
\hline
\end{tabular}

Table.8 Personal hygiene practices followed by adolescent girls during menstruation

\begin{tabular}{|l|l|l|l|}
\hline $\begin{array}{l}\text { Personal Hygiene } \\
\text { followed }\end{array}$ & Statement & Yes & No \\
\cline { 2 - 4 } & Taking bath & $83(69 \%)$ & $37(31 \%)$ \\
\cline { 2 - 4 } & $\begin{array}{l}\text { Washing hands after } \\
\text { changing }\end{array}$ & $47((39 \%)$ & $73(61 \%)$ \\
\cline { 2 - 4 } & Using Dettol soaps & $26(21 \%)$ & $94(79 \%)$ \\
\hline
\end{tabular}


Table.9 Physical Discomfort during Menstrual cycle

\begin{tabular}{|l|l|l|r|}
\hline S.No & \multicolumn{1}{|c|}{ Statements } & \multicolumn{1}{|c|}{ Yes } & No \\
\hline $\mathbf{1}$ & Itching & $63(53 \%)$ & $57(47 \%)$ \\
\hline $\mathbf{2}$ & Headache & $32(26 \%)$ & $88(74 \%)$ \\
\hline $\mathbf{3}$ & Nausea & $27(22 \%)$ & $93(78 \%)$ \\
\hline $\mathbf{4}$ & Muscle Cramps & $86(71 \%)$ & $34(29 \%)$ \\
\hline $\mathbf{5}$ & Stomach pain & $98(82 \%)$ & $22(18 \%)$ \\
\hline $\mathbf{6}$ & Rashes & $64(53 \%)$ & $56(47 \%)$ \\
\hline $\mathbf{7}$ & Legs/ Body pain & $52(43 \%)$ & $68(57 \%)$ \\
\hline $\mathbf{8}$ & Tiredness & $54(45 \%)$ & $66(55 \%)$ \\
\hline
\end{tabular}

Table.10 Method of disposal of used material in menstruation

\begin{tabular}{|l|l|l|}
\hline S.No & \multicolumn{1}{|c|}{ Satatement } & \multicolumn{1}{c|}{ Yes } \\
\hline $\mathbf{1}$ & $\begin{array}{l}\text { Throwing in dust } \\
\text { bin }\end{array}$ & $67(56 \%)$ \\
\hline $\mathbf{2}$ & Washing & $9(7 \%)$ \\
\hline $\mathbf{3}$ & Burning & $21(17 \%)$ \\
\hline $\mathbf{4}$ & Burying & $19(16 \%)$ \\
\hline $\mathbf{5}$ & Flushing & $4(3 \%)$ \\
\hline
\end{tabular}

Table.11 School Absenteeism during Menstrual period

\begin{tabular}{|l|l|l|}
\hline $\begin{array}{l}\text { How many days of } \\
\text { School missed during } \\
\text { periods? }\end{array}$ & $\mathbf{1 - 2}$ & $\mathbf{3 - 5}$ \\
\cline { 1 - 3 } & $58(48 \%)$ & $62(52 \%)$ \\
\hline
\end{tabular}

Table.12 Reasons for Absenteeism during Menstruation

\begin{tabular}{|l|l|l|}
\hline S.No & Statement & Yes \\
\hline $\mathbf{1}$ & Afraid of staining of cloths & $96(80 \%)$ \\
\hline $\mathbf{2}$ & Afraid of other makes you fun & $73(61 \%)$ \\
\hline $\mathbf{3}$ & No facilities for changing & $120(100 \%)$ \\
\hline $\mathbf{4}$ & Causes pain & $98(82 \%)$ \\
\hline $\mathbf{5}$ & Uncomfortable/ Tired & $88(73 \%)$ \\
\hline $\mathbf{6}$ & No facilities for disposal & $120(100 \%)$ \\
\hline $\mathbf{7}$ & Non availability of Pads & $76(63 \%)$ \\
\hline
\end{tabular}


Table.13 Awareness about Menstruation Knowledge

\begin{tabular}{|c|c|c|c|}
\hline S.No & Statement & Yes & No \\
\hline 1 & $\begin{array}{l}\text { Menstruation is a Physiological } \\
\text { condition }\end{array}$ & $98(82 \%)$ & $22(18 \%)$ \\
\hline 2 & Menstruation is disease & $67(56 \%)$ & $53(44 \%)$ \\
\hline 3 & Pregnant women Menstruate & $34(28 \%)$ & $86(72 \%)$ \\
\hline 4 & $\begin{array}{l}\text { Menstrual blood comes from } \\
\text { stomach/ where food is digested }\end{array}$ & $49(41 \%)$ & $71(59 \%)$ \\
\hline 5 & $\begin{array}{l}\text { Menstruation is Important for } \\
\text { getting pregnancy }\end{array}$ & $63(52 \%)$ & $57(48 \%)$ \\
\hline 6 & Menstrual blood is impure blood & $69(57 \%)$ & $51(43 \%)$ \\
\hline 7 & $\begin{array}{l}\text { Menstrual blood contain harmful } \\
\text { substances }\end{array}$ & $88(73 \%)$ & $32(27 \%)$ \\
\hline 8 & Menstruation is Sickness & $91(76 \%)$ & $29(24 \%)$ \\
\hline 9 & $\begin{array}{l}\text { Physical activities during } \\
\text { menstruation is harmful }\end{array}$ & $96(80 \%)$ & $24(20 \%)$ \\
\hline
\end{tabular}

Table.14 Activities missed during Menstrual period

\begin{tabular}{|l|l|l|}
\hline S.No & \multicolumn{1}{|c|}{ Statement } & \multicolumn{1}{c|}{ Yes } \\
\hline $\mathbf{1}$ & House hold work & $110(92 \%)$ \\
\hline $\mathbf{2}$ & Playing games or Sports & $105(87 \%)$ \\
\hline $\mathbf{3}$ & Spiritual activities & $113(95 \%)$ \\
\hline
\end{tabular}

Table.15 Menstrual Esteem of Adolescent girls

\begin{tabular}{|l|l|l|l|}
\hline S.No & \multicolumn{1}{|c|}{ Statement } & \multicolumn{1}{|c|}{ Yes } & \multicolumn{1}{c|}{ No } \\
\hline $\mathbf{1}$ & Happy with self & $27(22 \%)$ & $93(78 \%)$ \\
\hline $\mathbf{2}$ & Feel that you are not good & $86(72 \%)$ & $34(28 \%)$ \\
\hline $\mathbf{3}$ & $\begin{array}{l}\text { Feel you are as good as } \\
\text { others }\end{array}$ & $41(34 \%)$ & $79(66 \%)$ \\
\hline $\mathbf{4}$ & Feel like failure & $96(80 \%)$ & $24(20 \%)$ \\
\hline $\mathbf{5}$ & Low confidence levels & $77(64 \%)$ & $43(36 \%)$ \\
\hline $\mathbf{6}$ & Feel like exhausted & $91(76 \%)$ & $29(24 \%)$ \\
\hline $\mathbf{7}$ & Feel insecured & $112(93 \%)$ & $8(7 \%)$ \\
\hline $\mathbf{8}$ & Shameful & $92(77 \%)$ & $28(23 \%)$ \\
\hline $\mathbf{9}$ & Shyness & $94(78 \%)$ & $26(22 \%)$ \\
\hline
\end{tabular}

Conclusion and recommendations of the study are as follows:

Menstruation is an important indicator of reproductive health and development, thus menstrual hygienic practices are of major concern. Women manage menstruation differently when they are at home or outside; at homes, they dispose of menstrual products in domestic wastes and in public toilets and they flush them in the toilets without knowing the consequences of choking. So, there should be a need to educate and make them aware about the environmental pollution and health 
hazards associated with them. Implementation of modern techniques like incineration can help to reduce the waste. This study revealed that menstrual hygiene was unsatisfactory among adolescent girls. This was because of low level of education and improper assumptions about the phenomenon of menstruation.

Various schools, Anganwadi health centers, social welfare foundations, and nongovernment organizations should stand to disseminate awareness about menstrual hygiene, pattern, and problems. In our study, since the majority of the girls were school dropouts, knowledgeable parents play a vital role in implementing hygienic practices among adolescent girls. It is a strong belief that an educated woman is a first teacher of a family that is why education of the mother and the adolescent girl is very important. But presently, as we live in a male- dominated society, educating men about basic needs of women of his family during menstruation will help in contributing toward cleaner and healthier menstrual practices.

Study pointed towards the need for information on menstruation, especially about menarche before its onset and encouragement for the use of sanitary napkins as an absorbent. In the present study, majority of the respondents were school going and adolescent spends major time in their school. So teachers can play an influential role in informing them about changes during adolescence, especially about menarche and other issues related to menstruation. Sisters and mothers were the major source of information. Therefore, there is a strong need for the provision of comprehensive family life education for the parents also.

\section{References}

Barathalakshmi J, Govindarajan PK, Ethirajan
N, Felix AJ. Knowledge and practice of menstrual hygiene among school going adolescent girls. Natl J Res Commun Med 2014; 3:138-42.

Dudeja P, Sindhu A, Shankar P, Gadekar T. A cross-sectional study to assess awareness about menstruation in adolescent girls of an urban slum in western Maharashtra. International $\mathbf{J}$ Adolescent Medicine Health, 2016.

Juyal R, Kandpal SD, Semwal J, Negi KS. Practices of menstrual hygiene among adolescent girls in a district of Uttarakhand. Indian $\mathrm{J}$ Commun Health 2012; 24: 124-8.

Kansal S, Singh S, Kumar A. Menstrual hygiene practices in context of schooling: A community study among rural adolescent girls in Varanasi. Indian J Community Med 2016; 41: 39-44.

Patle RA, Kubde SS. Comparative study on menstrual hygiene in rural and urban adolescent. Int J Med Sci Public Health 2014; 3: 129-32.

Sharanya T. Reproductive health status and life skills of adolescent girls dwelling in slums in Chennai, India. Natl Med J India 2014; 27: 305-10.

Sharma S, Mehra D, Kohli C, Singh MM. Menstrual hygiene practices among adolescent girls in a resettlement colony of Delhi: A cross-sectional study. Int J Reprod Contracept Obstet Gynecol 2017; 6: 1945-51.9.

Sudeshna R, Aparajita D. Determinants of menstrual hygiene among adolescent girls: A multivariate analysis. Natl J Community Med 2012; 3: 294-301.

Wasnik VR, Dhumale D, Jawarkar AK. A study of the menstrual pattern and problems among rural school going adolescent girls of Amravati district of Maharashtra, India. Int J Res Med Sci 2015; 33:1252-6. 


\section{How to cite this article:}

Kavitha Kiran, V. and Yashoda, K. 2020. Menstrual Hygiene Management among Rural Adolescent Girls of Agrarian Families. Int.J.Curr.Microbiol.App.Sci. 9(01): 891-899. doi: https://doi.org/10.20546/ijcmas.2020.901.099 